\title{
Shock to a conspecific as an aversive stimulus
}

\author{
Stanley Wechkin, Jules H. Masserman, and William Terris, Jr.l \\ NORTHWESTERN UNIVERSITY MEDICAL SCHOOL
}

\begin{abstract}
This experiment confirms and extends an earlier finding that a hungry rhesus monkey (O) will avoid securing food if this subjects another monkey (SA) to electric shock. In the present series this "sacrificial", behavior was manifested in 6 of 10 animals independently of the relative position of the two animals in a dominance hierarchy. It was also found that while prior shock of the $O$ resulted in inhibition of responding following the introduction of shock to the SA, this variable was not correlated with the final manifestation of a sacrificial pattern. Introduction In a pilot study it was found that 6 of 8 hungry rhesus monkeys (Operators, or Os) avoided operating a switch for food when this caused another monkey (Stimulus Animal, or SA) of equal size to undergo electric shock. Inasmuch as animals frequently respond to shock with attack reactions (Ulrich \& Azrin, 1962), and since the two Os that were not inhibitedby shocked SAs of the same size did avoid shocking a much larger SA, the present experiment was designed to determine whether aversion to the shock of others would be maximized if the O was submissive to its SA. Data were also gathered on the effects of prior shock and the degree of familiarity between the two animals.
\end{abstract}

Subjects The Ss were 6 male and 4 female sexually immature rhesus macaques. For one year prior to and during the experiment, they were housed three to a cage as part of the larger colony.

The apparatus was a $5 \times 2 \times 2$ ft masonite and plexiglass box divided in the middle by a oneway screen that prevented vision from the right (SA) to the left $(\mathrm{O})$ compartment. The latter was equipped with red and blue stimulus lights, two chains suspended from ceiling microswitches, a food tube, and a water cup. The SA compartment was bare except for a floor grid attached to a Grason-Stadler E6070B shock source and scrambler.

Training The animals were trained to secure a $.7 \mathrm{gm}$ food pellet by pulling the left chain in response to a red light and the right chain after a blue one, each of $5 \mathrm{sec}$. duration, in the following steps: (a) Adaptation. The animals were given five daily $1 \mathrm{hr}$. sessions in which to adapt to the $\mathrm{O}$ compartment and associate the feeder click with delivery of food. (b) Single lever training. Five animals were initially trained to pull the right chain during the blue stimulus and five were trained to pull the left chain during the red. The stimuli were presented at an average interval of $30 \mathrm{sec}$; chain pulls between stimuli stopped the tape programmer controlling the stimulus presentation for $60 \mathrm{sec}$. Animals were run on alternate days after $22 \mathrm{hr}$. of food deprivation. Session length was set at a maximum of $90 \mathrm{~min}$., but stopped sooner if the animal did not respond for $5 \mathrm{~min}$. Following the attainment of criterial performance consisting of at least $90 \%$ correct trials and no more than 25 unsignalled chain pulls, the animals were trained on the other chain in the same manner and to the same criterion. (c) Discrimination training. The animals were presented with the red and blue light stimulus in random order at an average intertrial interval of $15 \mathrm{sec}$. If an O showed signs of positioning during this phase,i.e., consistently pulling one chain to the exclusion of the other, stimulus presentation for the preferred chain was halted until the O correctly responded to the other chain. Sessions were rundaily and were terminated when the $\mathrm{O}$ did not respond to five consecutive red and five consecutive blue stimuli. Animals were trained to a criterion of two consecutive sessions in which they responded correctly to $90 \%$ of the stimuli during a minimum of 50 trials and made fewer than 25 unsignalled responses.

Dominance testing and pairing After all animals had attained criterion in discrimination learning they were paired against each other in another apparatus and required to compete for 100 grapes presented one at a time. In most cases dominance was quickly established, the dominant animal getting better than $90 \%$ of the grapes. On the basis of this relationship, the animals were divided into five pairs, with dominance, sex and cagemate-noncagemate matchings balanced insofar as possible among the first and second members of the pairs.

Testing The first member of each pair was used as the $\mathrm{O}$ and the second as the SA during the first test period, and the roles were reversed during the second test period. The pairs were placed in their respective compartments and the $O$ was given a minimum of three days to adapt to the presence of the SA while continuing to perform at criterial level. After this, one of the chains was programmed not only to operate the feeder for $O$, but also to administer a 3 sec., 5 ma shock to the SA; whereas the other chain operated the feeder only. This programming was random, except where O had manifested a position habit, in which case the preferred lever was wired for shock to the SA. The animals were tested daily until one of the following two criteria was reached: (a) two consecutive sessions in which one chain was selected more frequently than the other (binomial $\mathrm{p}<.01$ ); or (b) two consecutive sessions in which relative response frequency was not significantly different at $<.25$ level. Since the number of correct responses per session at the end of training was almost never less than 50 , those with fewer were not included in this calculation. After an $\mathrm{O}$ had reached criterion, the roles of $\mathrm{O}$ and SA were re- 
Table 1. Effects of Interanimal Relationships and Shock on Response to the Shock of a Conspecific

\begin{tabular}{|c|c|c|c|c|c|c|c|c|c|}
\hline & \multirow{2}{*}{\multicolumn{3}{|c|}{$\begin{array}{l}\text { Position in } \\
\text { dominance }\end{array}$}} & \multirow[b]{2}{*}{ Test } & \multicolumn{5}{|c|}{$\begin{array}{c}\text { Correct responses during criterial } \\
\text { sessions }\end{array}$} \\
\hline & & & & & & 1 & & 2 & 2 \\
\hline $\mathrm{O}$ & Sex & $\mathrm{O}$ & SA* & Period & $\mathrm{CR}^{* *}$ & Shock & Nonshock & Shock & Nonshock \\
\hline 1 & $\mathrm{M}$ & 1 & $5 \mathrm{C}$ & 2 & 8 & 124 & 187 & 4 & 216 \\
\hline 2 & M & 2 & $9 \mathrm{NC}$ & 2 & 12 & 54 & 57 & 48 & 47 \\
\hline 3 & $\mathrm{M}$ & 4 & $3 \mathrm{C}$ & 2 & 9 & 39 & 71 & 32 & 174 \\
\hline 4 & $\mathbf{M}$ & 5 & $1 \mathrm{C}$ & 1 & 1 & 8 & 161 & 2 & 179 \\
\hline 5 & $\mathrm{~F}$ & 3 & $4 \mathrm{C}$ & 1 & 1 & 9 & 132 & 4 & 60 \\
\hline 6 & $\mathrm{M}$ & 7 & $10 \mathrm{C}$ & 1 & 2 & 11 & 41 & 9 & 73 \\
\hline 7 & M & 9 & $2 \mathrm{NC}$ & 1 & 1 & 15 & 43 & 18 & 85 \\
\hline 8 & $\mathrm{~F}$ & 6 & $8 \mathrm{NC}$ & 2 & 6 & 61 & 67 & 58 & 62 \\
\hline 9 & $\mathrm{~F}$ & 8 & $6 \mathrm{NC}$ & 1 & 1 & 57 & 62 & 81 & 73 \\
\hline 10 & $\mathrm{~F}$ & 10 & $7 \mathrm{C}$ & 2 & 3 & 57 & 51 & 61 & 66 \\
\hline
\end{tabular}

versed as noted and the new $O$ was tested in an identical manner following adaptation.

Results The number of successive sessions during which $\mathrm{O}$ responded minimally after one of its chain pulls was coupled with shock to the SA, and the number of correct shock and nonshock trials during the criterial sessions are shown in Table 1 . Os $1,3,4,5,6$, and 7 selectively responded to the nonshock chain and sacrificed a significant number of opportunities to obtain food in order to avoid shocking the SA. Of the remaining four Os, all responded either selectively and/or with lower latencies to the nonshock chain during some of the test sessions before stabilizing in a non-differential pattern.

"Sacrificial" responding, using critical performance as an indicator, was not significantly related to submissiveness, in that 2 of the 4 indifferent Os were submissive, whereas 4 of the 6 inhibited Os were dominant to their SAs. By comparison, the familiarity variable approached significance: 5 of the 6 differential responders had been cagemates of their SAs, whereas 3 of the 4 nondifferentiators had not (Fisher-Yates $P=.119$ ). Also of interest is the finding that the Os during the second test period (i. e., those that had served as SAs during the first test period and received 20-300 shocks) took significantly longer to resume responding after the introduction of shock to their SAs, and went with minimal food for an average of 7.6 days, as compared to 1.2 days for Os that had received no prior shock (Mann-Whitney $\mathrm{U}=\mathrm{O}, 2$ sided $\mathrm{P}<.01$ ). This behavior of the shocked Os was not attributable to an acquired aversion to the apparatus itself since they showed no decrement in chain-manipulation during the adaptation sessions immediately following their shock.

Diseussion Inasmuch as relative dominance did not affect food-avoidance it may be inferred that the Os were not deterred by the threat mimetics of the SAs; nor, since the SAs vocalized infrequently, is it probable that an increased noise level was the aversive stimulus [cf., the criticism by Lavery \& Foley (1963) of the "'altruism", in rats reported by Rice \& Gainer (1962)]. Church (1959) and Mirsky et al. (1958) demonstrated that an animal can be negatively conditioned to observing another in shock if it experienced shock simultaneously; it is therefore possible that our inhibited Os had acquired pre-experimental aversive reactions in this manner. That the familiarity variable approached statistical significance would tend to bear this out, since this contingency would have been more likely to occur with a cagemate. It is also possible that aversion to the perceived pain of conspecifics may be an ethologically innate pattern that serves to preserve the species, except where, as in the wild state, the threat or infliction of pain is necessary for the establishment of territoriality, dominance, etc.-conditions not present in this experiment.

Church also suggests that prior shock may result in an animal generalizing the perception of its own reactions to others; however, this does not explain our finding that 3 of the 5 previously shocked Os did not show differential responding, whereas only one of the nonshocked Os failed to exhibit this. Church's conditioning explanation may therefore apply to the initial inhibition of the Os, but with the resumption of chain manipulation as hunger increased, the incidence of differential responding must be attributed to other variables.

\section{References}

CHURCH, R. M. Emotional reactions of rats to the pain of others. J. comp. physiol. Psychol., 1959, 52, 132-134.

LAVERY, J. J., \& FOLEY, P. J. Altruism or arousal in the rat? Science, 1963, 140, 172-173.

MIRSKY, I. A., MILLER, R. E., \& MURPHY, J. V. The communication of affect in rhesus monkeys. J. Amer Psychoanal. Assn., 1958, 6, 433-441.

RICE, G. E., \& GAINER, PRISCILLA "Altruism" in the albino rat. J. comp. physiol. Psychol., 1962, 55, 123-125.

ULRICH, R. E., \& AZRIN, N. H. Reflexive fighting to aversive stimulation. J. exp. Anal. Beh., 1962, 5, 511-520.

$$
\text { Note }
$$

1. This work was supported by Grant 1719 from the Mental Health Fund of the Illinois Department of Public Welfare and USPHS Grant M 2312. Eduard H. Schludermann assisted in the collection of data. 